\title{
Fatal injury due to unrestrained vehicle load
}

\author{
David Teanby
}

\section{Case report}

A 69 year old male commercial courier driving an estate car on the M6 motorway was struck from behind by a heavy goods vehicle travelling at $50 \mathrm{mph}$ (tachograph). The rear seats of the vehicle were down to permit carriage of an industrial refrigeration unit roughly the size and weight of a small domestic refrigerator.

The impact of the crash accelerated the refrigeration unit into the rear of the driver's seat. This caused deformation of the frame, propelled the driver forwards, and effectively crushed him between the seat and his seat belt (fig 1).

Department of Orthopaedic Surgery, University Hospital of South Manchester, Wythenshawe Hospital, Southmoor Road, Manchester M23 9LT, UK

D Teanby
On admission he was noted to be hypotensive, semiconscious, and to have a complete $\mathrm{T} 9$ paraplegia. No details of the accident mechanism were relayed to the hospital. His conscious level and hypotension responded rapidly to infusion of colloid. Radiographs of chest, skull, and lumbar and thoracic spine showed no abnormality other than a widening of the mediastinum thought to be acceptable on a portable AP film. Computed tomography scan of the thoracic spine was reported as showing no fracture but a large paraspinal mass thought to be neoplastic was noted.

Elective ventilation was commenced for respiratory failure and he died 11 days after the accident, subsequent to an asystolic cardiac arrest.

At post mortem examination he was found to have a transverse shear fracture of the body of T9 (fig 2) with severance of the spinal cord and a complete transection of the aorta at this level. The paraspinal mass was a haematoma from the aortic rupture.

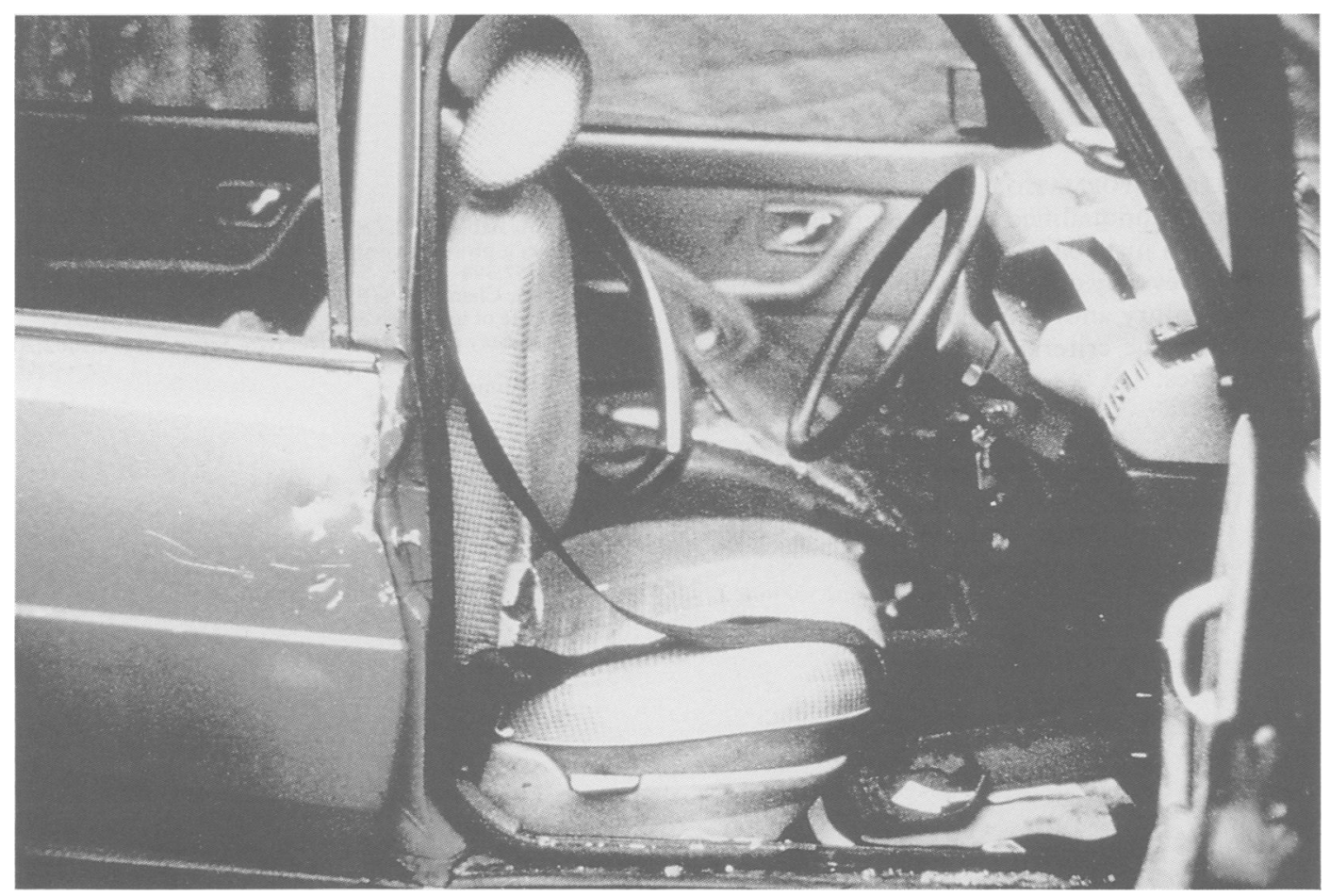

Figure 1 Driver's seat showing deformation of seat frame. 


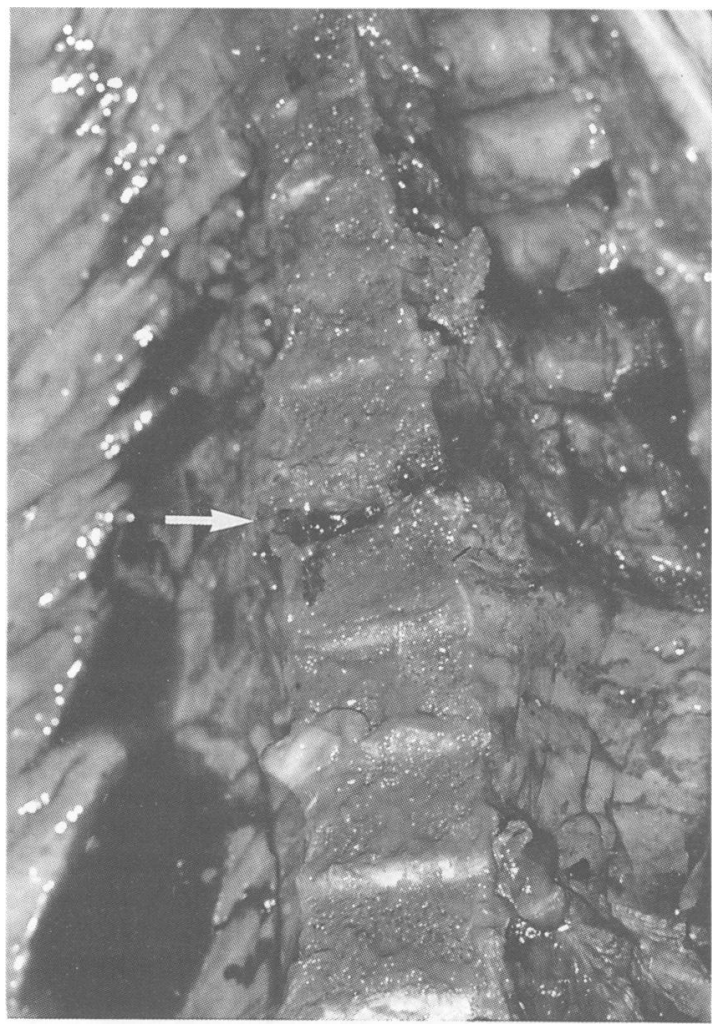

Figure 2 Thoracic spine after longitudinal section. The fracture has remained in alignment.

\section{Discussion}

PRE-HOSPITAL INFORMATION

The use of the unqualified term road traffic accident driver or even just road traffic accident is no longer acceptable. Severity of injury may be directly related to cause of injury and vehicular damage. ${ }^{2}$ Pre- and in-hospital triage criteria can be based on accident characteristics.

\section{LACK OF LOAD RESTRAINT}

Currently no requirements for restraint of loads within cars or light goods vehicles in the United Kingdom exist. Load restraining hooks in estate cars are provided by a few manufacturers-for example, Volvo, Audi, and Rover.

There are no requirements for the front seats to withstand loading of this nature from behind.

\section{COMMERCIAL USE OF LIGHT VEHICLES}

The use of cars and light vans for commercial purposes are not governed by regulations for construction or modifications. Commercial drivers of small vehicles are not governed by hours of work and rest regulations such as those applied to drivers of heavy goods vehicles.

The driver in this accident was travelling from Scotland to the west Midlands when the accident occurred near Manchester at $2.00 \mathrm{am}$. Police investigation of the circumstances of the accident, indicated that it is possible that he fell asleep at the wheel; this may be the cause of $20 \%$ of nocturnal road traffic accidents. ${ }^{3}$

The introduction of legislation to control hours of work and rest periods for all commercial drivers, measurement with devices similar to heavy goods vehicle tachographs, and the use of suitably modified vehicles for commercial purposes may be appropriate.

I thank the Officers of Cheshire constabulary for their assistance.

1 Fox MA, Fabian TC, Croce MA, et al. Anatomy of the accident scene; a prospective study of injury and mortality. Am Surg 1991;57:394-7.

2 Jones IA, Champion HR. Trauma triage: vehicle damage as an estimate of injury severity. $J$ Trauma $1989 ; 29: 646-53$.

3 Horne J. Stay awake, stay alive. New Scientist 1992;1802:20-4.

Accepted 29 June 1992 